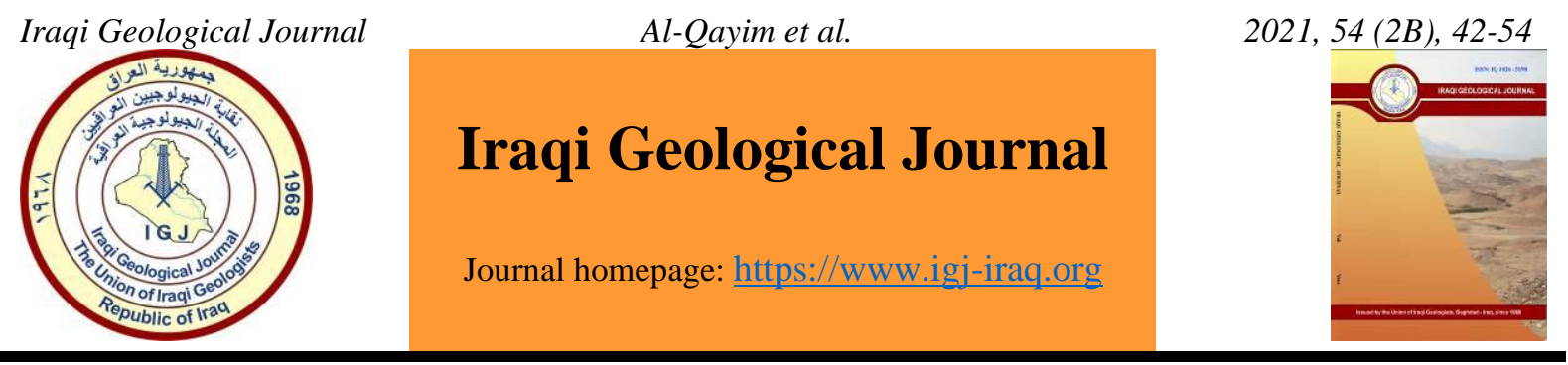

\title{
Evaluation of Reservoir Fluids Mobility, Mauddud Reservoir (Albian), Khabbaz Oil Field, Kirkuk Area, NE Iraq
}

\author{
Basim Al-Qayim $^{1, *}$, Fouad Qader ${ }^{1}$ and Fawzi M. O. Albeyati ${ }^{2}$ \\ ${ }^{1}$ Department of Petroleum Engineering, Komar University of Science and Technology, Sulaymaniyah, Kurdistan, Iraq \\ ${ }^{2}$ Technical Engineering College of Kirkuk, North Technical University, Kirkuk, Iraq \\ * Correspondence: basim.alqayim@univsul.edu.iq
}

Received: 11 October 2020; Accepted: 16 May 2021; Published: 31 August 2021

\begin{abstract}
The Albian Mauddud reservoir of the Khabbaz Oil Field is consisting of $170 \mathrm{~m}$ alternating shelf carbonates and pervasive dolomite horizons of coarse to fine crystalline mosaic. Core analysis and log measurements reveal the occurrence of three electrofacies units (A, B, and C) with variable petrophysical properties. Unit A with good reservoir quality shows average porosity of $18.8 \%$ and average permeability of $27.5 \mathrm{md}$. The other two units (B and C) are less attractive and have an average porosity of $9.6 \%$ and $9.2 \%$ consequently. Pore size ranges between macro to meso types and related mainly to vugs, fractures and intercrystalline porosity, especially in the dolomite units. The reservoir fluids saturation, bulk volume, and mobility are evaluated using resistivity logs measurements and porosity logs (Neutron-Density porosities) in addition to other reservoir laboratory data. Calculations and cross data plotting of the related petrophysical parameters were applied to the three units of the Mauddud reservoir in seven wells of the field. It shows an overall good reservoir fluids mobility. Results indicate that the formation water of Khabbaz Oil Feld is a non-movable type especially for the crestal wells which make most of these wells produce water-free hydrocarbon. Variability within well's hydrocarbon mobility is noticed and related to units and subunits lithology and porosity variation. Other variations seem to be related mainly to permeability, pores geometry and variability of water saturation in addition to the location of well with respect to oil pool within the field structure.
\end{abstract}

Key Words: Reservoir fluids; Mauddud; Khabbaz; Kirkuk; Albian; Iraq

\section{Introduction}

The Khabbaz field is estimated to contain more than 500 million bbl of oil reserve within the main reservoir packages (the Cretaceous and Tertiary reservoirs) and thus considered as a giant oil field (Verma, et al., 2004). The producing reservoirs of the field include: (i) the Oligocene (Kirkuk Group) and the Miocene (Jerribe Formation) with 36o API oil in a 130-m column, (ii) the Upper Qamchuqa (Mauddud) Formation with $29^{\circ}$ API oil in a $125-\mathrm{m}$ column, and (iii) the third reservoir belong to Aptian Lower Qamchuqa (Shu'aiba) Formation) with 42 API $^{\circ}$ oil in a 175-m) Bayphase, 2011). The first discovery well (Kz-1) was drilled in August 1976, and field development was started in 1987 by France's Technip Geoproduction for the North Oil Company. The Khabbaz Field can produce about 25,000 barrels of oil per day and $45 \mathrm{MCF} / \mathrm{d}$ of gas (APS Review, 2007). The Khabbaz structure is located

DOI: $10.46717 /$ igj.54.2B.4Ms-2021-08-24 
about $20 \mathrm{~km}$ WNW of Kirkuk City in northern Iraq, to the southwestward of the giant Kirkuk structure (Fig. 1).

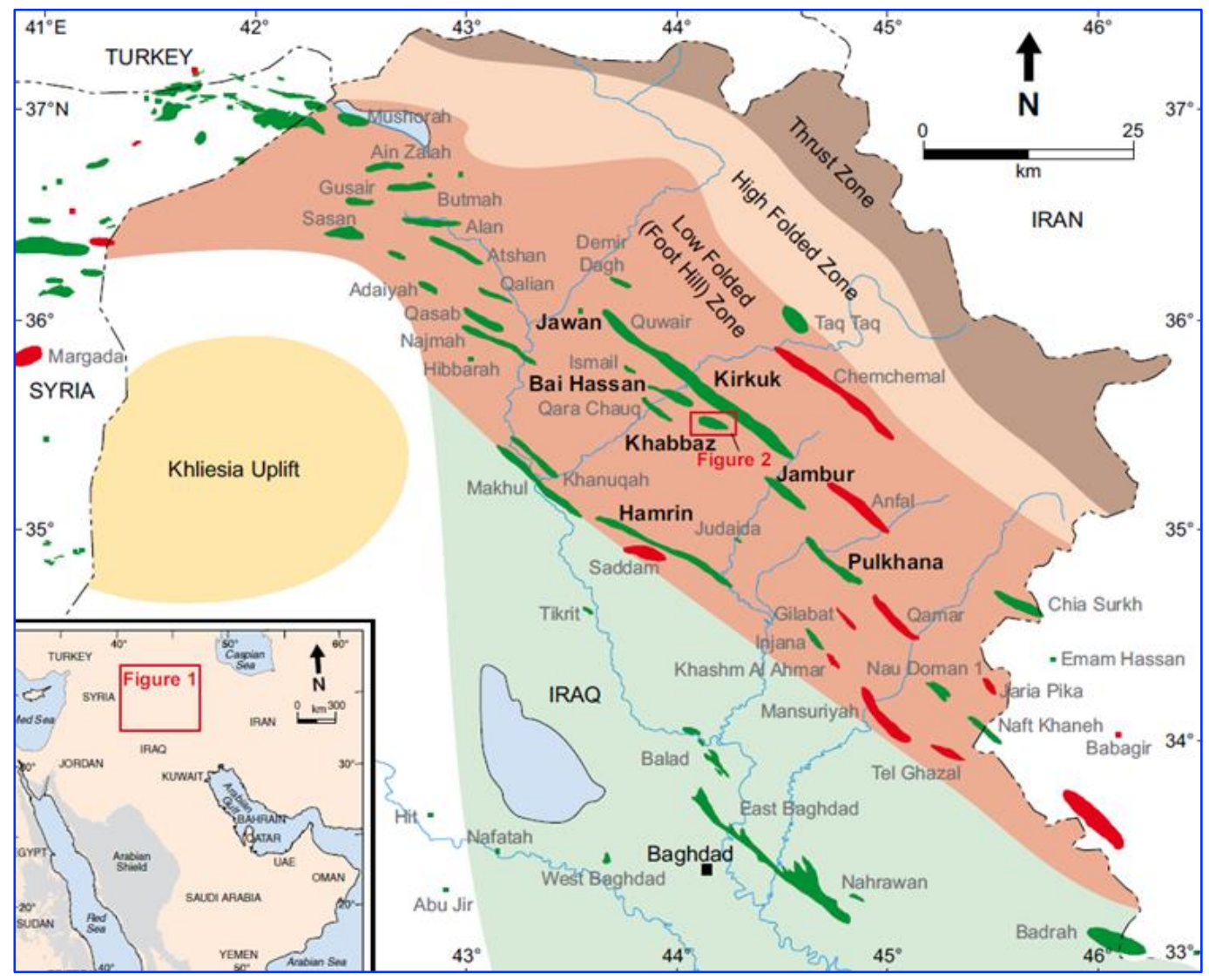

Fig. 1. Regional tectonic map of northern Iraq showing the location of the Khabbaz oil field, SW of Kirkuk (Al-Qayim et al., 2010).

The structure of the Khabbaz oil field represents a domal anticline $20 \mathrm{~km}$ long and $4 \mathrm{~km}$ wide with a slightly curving axis (Fig. 2). A major fault intersects the structure to the southeast plunge, and has had a significant influence on reservoir production performance (NOC, 1996). Forty wells so far have been drilled at the Khabbaz Field, most of them have targeted the Tertiary reservoirs, although some wells have penetrated the Cretaceous Qamchuqa carbonates (the Mauddud and Shuaiba reservoirs). The field is reported to currently produce about 25,000 Mbbl/d of oil and $45 \mathrm{MCF} / \mathrm{d}$ of gas (APS Review, 2007).

One of the most important functions of reservoir geology is the periodic calculation of the reservoir oil and gas in place and the recovery of its fluids (Hamada, 2006). Oil recovery is a reflection of the mobility of hydrocarbons through porous media. This mobility is controlled by reservoir rocks, fluid properties, and pressure gradient. Oil in place is calculated either by the volumetric method or by material balance equation. The main controlling factors that influence the occurrence characteristics of movable fluids are demonstrated to be reservoir physical property, pore type, pore and throat radii, porethroat radius ratio, sorting coefficient, effective pore-throat volume, and clay mineral filling (Li, 2018). Similar studies on Iraqi reservoirs become increasingly important such as Abdulrahman et al. (2020) on Jeribe Formation in Jeria Pika gas field, and Mamaseni (2020) on the Sargelu reservoir in Atrush oil field. The purpose of this work is to evaluate fluids mobility and its relations to the Mauddud reservoir petrophysical property. It is the first time that such a study is conducted on the Khabbaz oil field fluids. 


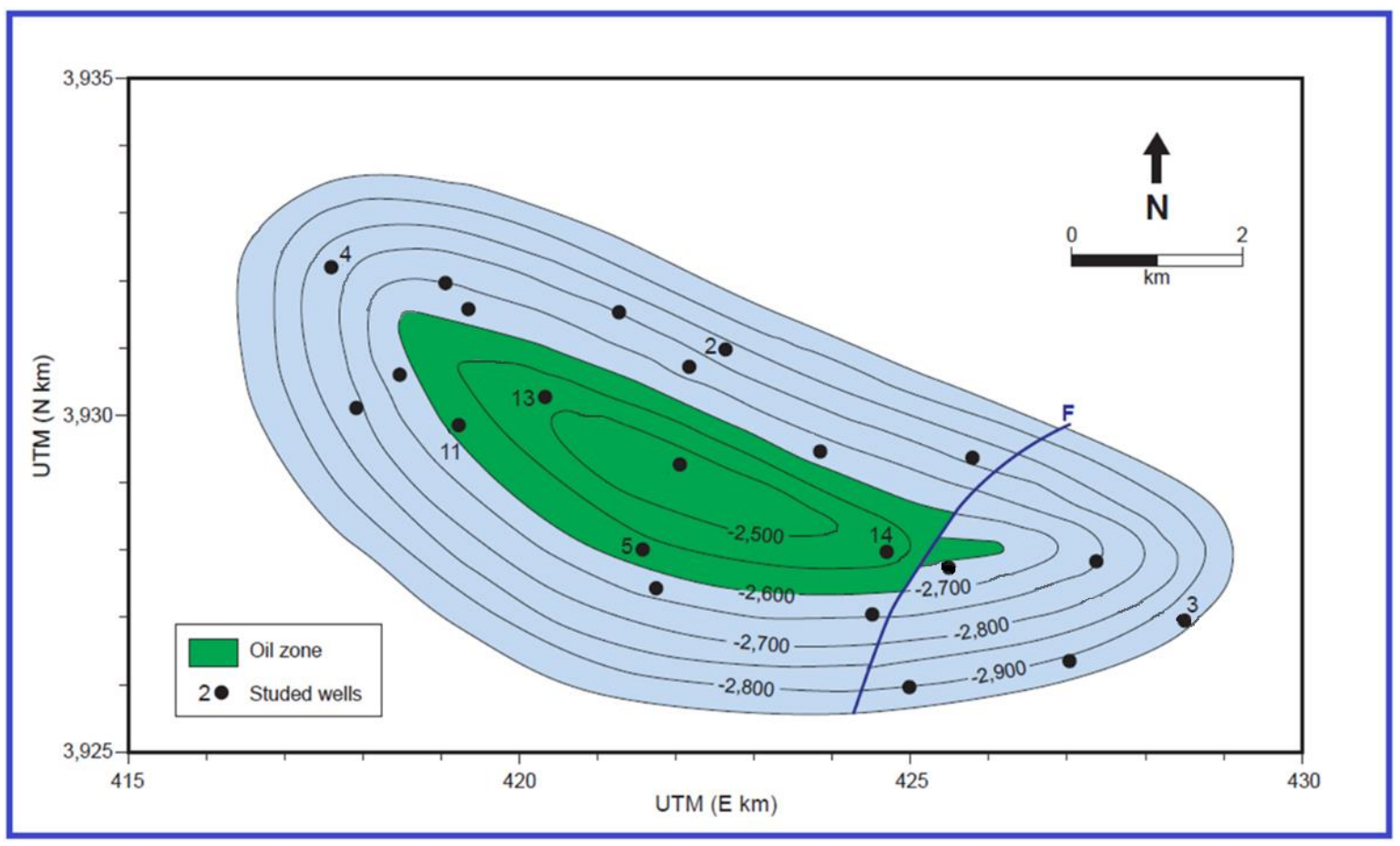

Fig. 2. Generalized structural contour map of Khabbaz Field on top of the Upper Qamchuqa (Mauddud) Formation showing the general area of oil zone (Al-Qayim et al., 2010).

\section{Stratigraphic Setting}

\subsection{Mauddud Reservoir}

The Qamchuqa Formation of the mountain area is considered by Al-Sadooni (1978) as Qamchuqa Group at Kirkuk area and subdivided into three formations from bottom: Lower Qamchuqa (Shu'aba Formation), Upper Sarmord (Nahr Umr Formation), and Upper Qamchuqa (Mauddud Formation). This new scheme was adopted by most petroleum geologists working in the Kirkuk area and amended by Buday (1980). The Mauddud Formation is a widespread Late Albian unit, which extends over most of the Arabian Platform (Sadooni and Alsharhan, 2003). In Iraq, the thickness varies due to lateral facies changes and erosional truncation. The thickest area of the formation is located to the northeast of Kirkuk City, where it increases from $170 \mathrm{~m}$ in the Khabbaz field, to $237 \mathrm{~m}$ in Kirkuk-107 Well, to $250 \mathrm{~m}$ in well Chemchamal-1 (Al-Sadooni, 1978). The general lithology of the formation within the Kirkuk area shows no significant variation. It is generally characterized by intercalations of limestone, dolomitic limestone, and dolostone with infrequent marl intercalations (Fig. 3). These carbonates developed over an extensive ramp along the margin of the Arabian Plate, which evolved during the Albian time (Jassim and Goff, 2006). In the Khabbaz field the lower contact of the Mauddud Formation is conformable and gradational with the Upper Sarmord (Nahr Umr) Formation. The upper contact with the Dokan Formation is marked by a break corresponding to either non-deposition or an erosional unconformity (Al-Qayim et al., 2010).

The Mauddud Formation in Khabbaz field ranges between 156-180 $\mathrm{m}$ in thickness with an average of $167.6 \mathrm{~m}$ (Table 1). The Formation here shows heterogeneity with variable lithologic characters and variable associated porosities. In southern Iraq, the Mauddud reservoir hydrocarbon movability is hampered by excessive shale occurrences (Khudhair and Al-Zaidy, 2018). Pore size, in general ranges between macro to meso types and related mainly to vugs, fractures and intercrystalline porosity especially in the dolomite units (Al-Qayim et al., 2010) 


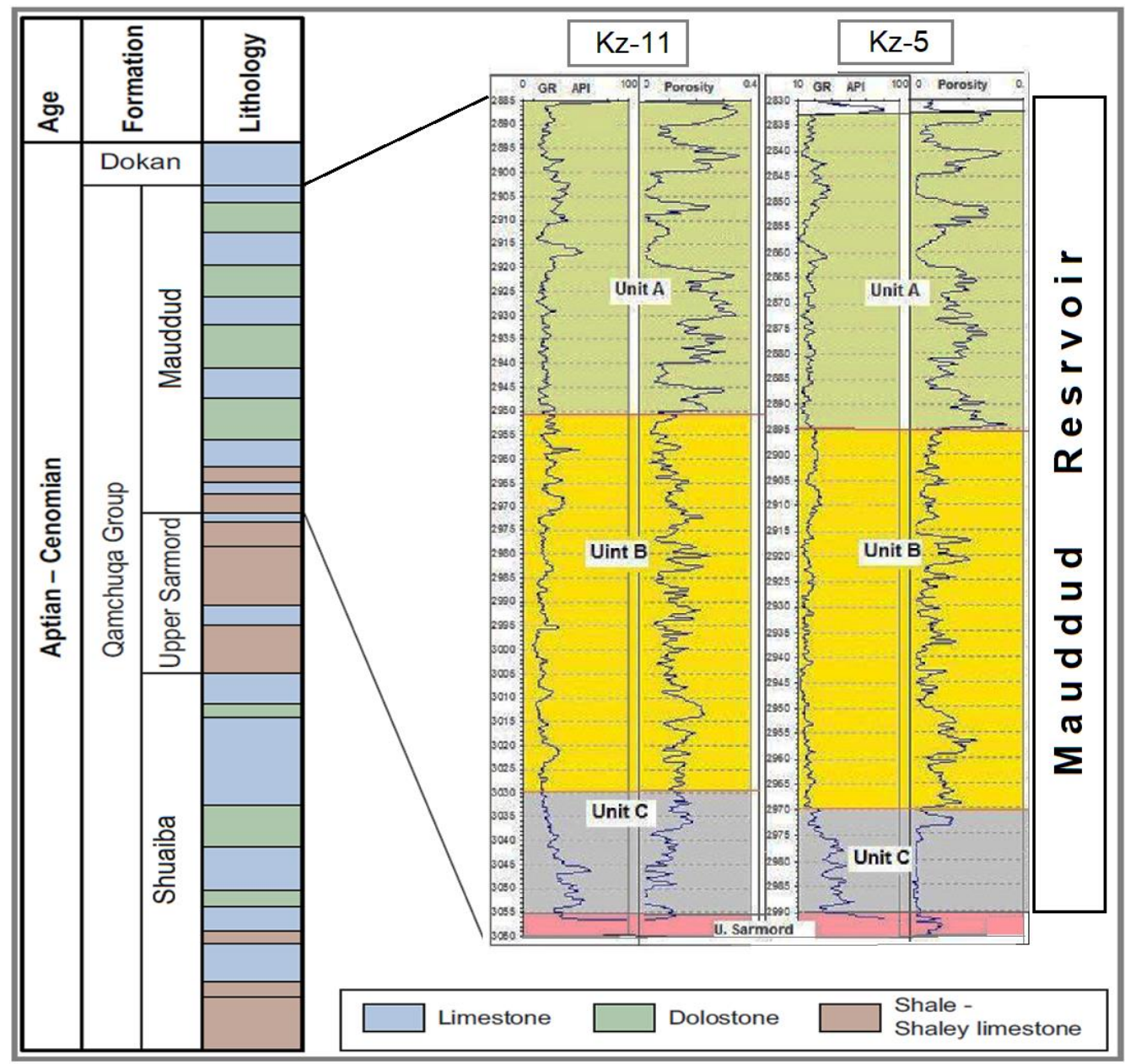

Fig. 3. General stratigraphic column of the Qamchuqa Group showing the formations, lithologies, logs characters, and units of the Mauddud reservoir, in two of the studied wells, Khabbaz Oil Field

\subsection{Reservoir Units}

Al-Qayim et al. (2010) had predicted three different reservoir units with distinctive lithology and porosity values. They have used core analysis and microfacies examination assisted by interpretation of set of well logs. The following review based on their description of the Mauddud reservoir at Khabbaz Oil Field.

Unit A represents the upper lithologic part of the reservoir. It ranges in thickness from 48 to $68 \mathrm{~m}$. (Table 1). It is generally characterized by buff brown, soft, sucrose, vuggy, and fine to medium crystalline dolomite and dolomitic limestone alternating with light gray, hard, dense, fossiliferous and occasionally bioturbated limestone. It is characterized by high porosity intervals with average values of subunits ranging from $14 \%$ to $21 \%$ (Table 2).

Unit B represents the middle and the thickest part of the reservoir. It ranges in thickness between 71.5 and $79.5 \mathrm{~m}$. It consisting of alternations of dolostone, dolomitic limestone and limestone with subsidiary intercalations of thin marly limestone. The dolostones are represented by irregular horizons of buff, medium hard, sucrosic, fine to coarse crystalline dolomite. It has fair porosity of average values of the subunits around $10 \%$.

Unit $C$ is the thinnest unit and ranges between 19.5 and $42.0 \mathrm{~m}$ (Table 1). It generally consists of alternating light gray to whitish gray, hard, bioturbated, fossiliferous, and occasionally marly or dolomitic limestone and dolostone with dark gray to black fissile and friable shale or marlstone. The 
argillaceous content is usually variable but generally increases downward. Due to low thickness, the unit is not divided into subunits. Its porosity does not exceed 10\% (Table 2).

Table 1. Drilling intervals and thickness of the of the reservoir units of the Mauddud Formation, Khabbaz Field. (Al-Qayim et al., 2010)

\begin{tabular}{|c|c|c|c|c|}
\hline Wells & Mauddud interval and thickness (m) & Unit & Interval (m) & Thickness (m) \\
\hline \multirow{3}{*}{$\mathrm{Kz}-2$} & \multirow{3}{*}{$\begin{array}{c}3025.5-3205 \\
179.5\end{array}$} & A & $3025.5-3091.5$ & 66 \\
\hline & & $\mathrm{B}$ & $3091.5-3163$ & 71.5 \\
\hline & & $\mathrm{C}$ & $3163-3205$ & 42 \\
\hline \multirow{3}{*}{$\mathrm{Kz}-3$} & \multirow{3}{*}{$\begin{array}{l}3202-3250 \\
\quad 48\end{array}$} & A & $3202-3250$ & 48 \\
\hline & & B & & \\
\hline & & $\mathrm{C}$ & & \\
\hline \multirow{3}{*}{$\mathrm{Kz}-4$} & \multirow{3}{*}{$\begin{array}{l}2979-3150 \\
171\end{array}$} & A & 2979-3047 & 68 \\
\hline & & B & $3047-3120$ & 73 \\
\hline & & $\mathrm{C}$ & $3120-3150$ & 30 \\
\hline \multirow{3}{*}{$\mathrm{Kz}-5$} & \multirow{3}{*}{$\begin{array}{l}2832-2991 \\
159\end{array}$} & A & $2832-2895$ & 63 \\
\hline & & $\mathrm{B}$ & $2895-2969$ & 74 \\
\hline & & $\mathrm{C}$ & $2969-2991$ & 22 \\
\hline \multirow{3}{*}{$\mathrm{Kz}-11$} & \multirow{3}{*}{$\begin{array}{c}2885-3057 \\
171.5\end{array}$} & A & $2885.5-2950.5$ & 65 \\
\hline & & B & $2950.5-3030$ & 79.5 \\
\hline & & $\mathrm{C}$ & $3030-3057$ & 27 \\
\hline \multirow{3}{*}{ Kz-14 } & \multirow{3}{*}{$\begin{array}{l}2811.5-2968 \\
156.5\end{array}$} & A & $2811.5-2873.5$ & 62 \\
\hline & & B & $2873.5-2948.5$ & 75 \\
\hline & & $\mathrm{C}$ & $2948.5-2968$ & 19.5 \\
\hline
\end{tabular}

Table 2. Thicknesses and porosities values of the subunits of the Maudud reservoir, Khabbaz field (Al-Qayim et al., 2010)

\begin{tabular}{|c|c|c|c|c|c|c|c|c|c|}
\hline $\begin{array}{l}\text { Litho } \\
\text { Unit }\end{array}$ & Reservoi & sub-Unit & Kz-2 & Kz-3 & Kz-4 & Kz-5 & Kz-11 & Kz-14 & $\begin{array}{l}\text { Average } \\
\text { Value }\end{array}$ \\
\hline \multirow{12}{*}{ Unit A } & \multirow{2}{*}{ A1 } & Thickness & 1.5 & 4.2 & 8 & 2.7 & 4.7 & 4 & 3.85 \\
\hline & & Porosity & 0.18 & 0.19 & 0.22 & 0.21 & 0.26 & 0.14 & 0.2 \\
\hline & \multirow{2}{*}{ A2 } & Thickness & 5.8 & 10.9 & 10.4 & 5.9 & 5.7 & 6.8 & 7.55 \\
\hline & & Porosity & 0.27 & 0.17 & 0.18 & 0.18 & 0.21 & 0.24 & 0.21 \\
\hline & \multirow{2}{*}{ A3 } & Thickness & 8.7 & 9.2 & 4 & 8 & 2.3 & 1.7 & 5.56 \\
\hline & & Porosity & 0.17 & 0.18 & 0.12 & 0.18 & 0.16 & 0.18 & 0.16 \\
\hline & \multirow{2}{*}{ A4 } & Thickness & 10.2 & 9.5 & 14.2 & 10.5 & 11.8 & 21.2 & 12.9 \\
\hline & & Porosity & 0.14 & 0.14 & 0.19 & 0.16 & 0.22 & 0.2 & 0.175 \\
\hline & \multirow{2}{*}{ A5 } & Thickness & 12.5 & & 8.8 & 13 & 8.5 & 11.9 & 10.94 \\
\hline & & Porosity & 0.17 & & 0.14 & 0.16 & 0.19 & 0.15 & 0.162 \\
\hline & \multirow{2}{*}{ A6 } & Thickness & 9.2 & & 28.1 & 8.8 & 6.9 & 6.8 & 11.86 \\
\hline & & Porosity & 0.13 & & 0.11 & 0.19 & 0.17 & 0.1 & 0.14 \\
\hline \multirow{6}{*}{ Unit B } & \multirow{2}{*}{ B1 } & Thickness & 2 & & 17 & 10.5 & 11.5 & 5.3 & 9.26 \\
\hline & & Porosity & 0.1 & & 0.07 & 0.1 & 0.06 & 0.15 & 0.1 \\
\hline & \multirow{2}{*}{ B2 } & Thickness & 3.4 & & 14 & 7.4 & 5.6 & 2.1 & 6.48 \\
\hline & & Porosity & 0.11 & & 0.08 & 0.07 & 0.11 & 0.08 & 0.086 \\
\hline & \multirow{2}{*}{ B3 } & Thickness & 1.9 & & 23.6 & 18 & 19 & 12.4 & 14.98 \\
\hline & & Porosity & 0.15 & & 0.1 & 0.12 & 0.1 & 0.08 & 0.11 \\
\hline \multirow{2}{*}{ Unit C } & \multirow{2}{*}{$\mathrm{C} 1$} & Thickness & 8.6 & & 18.2 & 2.2 & 7.9 & 2 & 7.78 \\
\hline & & Porosity & 0.1 & & 0.08 & 0.12 & 0.09 & 0.11 & 0.1 \\
\hline
\end{tabular}

\section{Materials and Methods}

Data for this research were selected from six wells of Khabbaz oil field: Kz-4, Kz-11, Kz-5, Kz-2, $\mathrm{Kz} 14$ and Kz-3. Additional $\log$ data of part of reservoir section from well Kz-13 were also used to support bulk volume of water evaluation. The selection of these wells is based on the availability of the 
resistivity log data. Lithologic and petrographic review of the studied reservoir is mainly based on the detailed account given for the same reservoir by Al-Qayim et al. (2010). Different types of well logs were examined for this study including; neutron, density, and sonic logs to evaluate reservoir porosity variations using Getdata222exe hardware log graph. Variable types of resistivity log were analyzed to measure formation resistivity parameters. Measurements of the resistivity of flushed zone and uninvaded zone were calculated. In this study, deep (Rt), and shallow (Rxo) resistivity data obtained from Dual Laterolog Deep (LLD) and Micro Spherical Focused log ( $\mu$ SFL), respectively and in some of the studied wells they had been replaced by Induction Electrical Log (Short Normal and Induction). The values of the drilling mud filtrate resistivity $(\mathrm{Rm})$ and mud filtrate resistivity of flushed zone $(\mathrm{Rmf})$ and the uninvaded formation water resistivity ( $\mathrm{Rw}$ ) were corrected to well temperature using N.O.C. laboratory measurements (Table 3 ). These parameters were used with resistivity log data to calculate the fluids saturation, bulk volume of water, bulk volume of hydrocarbon, movable hydrocarbon fraction and residual hydrocarbon fraction according to equations set by Asquith and Krygowski, (2004). Resistivity in addition to other formation parameters $(a, n)$ were used to calculate the formation water saturations ( $\mathrm{Sw}$ and $\mathrm{Sxo}$ ). The cementation factor $(\mathrm{m})$ is estimated using laboratory measured data carried out by Northern Oil Company.

Table 3. Correction of Rmf and Rw into formation temperature (N.O.C, 2008)

\begin{tabular}{lcccc}
\hline Wells & $\begin{array}{c}\boldsymbol{R} \boldsymbol{m} \boldsymbol{f}(\boldsymbol{\Omega} . \mathbf{m}) \text { at } \\
\text { temperature }\end{array}$ & $\begin{array}{c}\text { Corrected Rmf to } \\
\text { the temperature }\end{array}$ & $\begin{array}{c}\text { Rw }(\boldsymbol{\Omega} \text { m) at measured } \\
\text { temperature }\end{array}$ & $\begin{array}{c}\text { Corrected Rw to the } \\
\text { formation temperature }\end{array}$ \\
\hline $\mathrm{Kz}-1$ & 0.474 at $112 \mathrm{~F}^{\circ}$ & $0.26(\Omega . \mathrm{m})$ & & \\
$\mathrm{Kz}-2$ & 0.703 at $88 \mathrm{~F}^{\circ}$ & $0.31(\Omega . \mathrm{m})$ & $\mathrm{Rw}=0.022$ at $218 \mathrm{~F}^{\circ}$ & $0.023(\Omega . m)$ \\
$\mathrm{Kz}-3$ & & & $\mathrm{Rw}=0.024$ at $200 \mathrm{~F}^{\circ}$ & $0.023(\Omega . \mathrm{m})$ \\
$\mathrm{Kz}-4$ & 0.505 at $77 \mathrm{~F}^{\circ}$ & $0.20(\Omega . \mathrm{m})$ & $\mathrm{Rw}=0.024$ at $200 \mathrm{~F}^{\circ}$ & $0.023(\Omega . \mathrm{m})$ \\
$\mathrm{Kz}-5$ & 0.108 at $72 \mathrm{~F}^{\circ}$ & $0.0397(\Omega . \mathrm{m})$ & & \\
$\mathrm{Kz}-7$ & 0.527 at $52 \mathrm{~F}$ & $0.1446(\Omega . \mathrm{m})$ & & \\
$\mathrm{Kz}-11$ & 0.461 at $27.7 \mathrm{C}^{\circ}$ & $0.19(\Omega . \mathrm{m})$ & & \\
$\mathrm{Kz}-13$ & 0.558 at $22.2 \mathrm{C}^{\circ}$ & $0.2039(\Omega . \mathrm{m})$ & & \\
$\mathrm{Kz}-14$ & 0.341 at $24.4 \mathrm{C}^{\circ}$ & $0.1309(\Omega . \mathrm{m})$ & & \\
$\mathrm{Kz}-16$ & 0.334 at $61 \mathrm{C}^{\circ}$ & $0.2317(\Omega . \mathrm{m})$ & & \\
\hline
\end{tabular}

\section{Results}

\subsection{Water and Oil Saturation Calculations}

Water saturation ( $\mathrm{Sw}$ ) of the reservoir's uninvaded zone is calculated by the Archie (1942) formula (in Asquith and Krygowski, 2004) as follow:

$$
S w=\left[\left(a^{*} R w\right) /\left(R t^{*} \Phi^{m}\right)\right]^{1 / \mathrm{n}}
$$

Where:

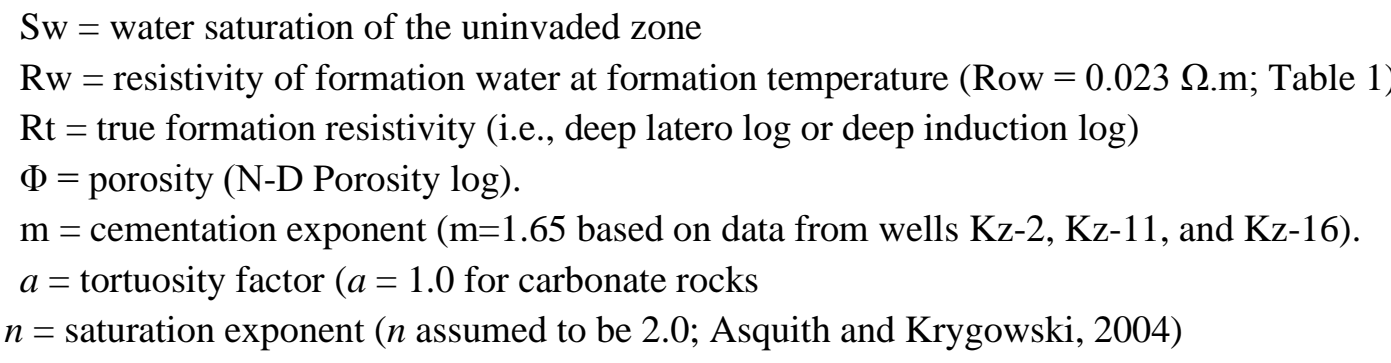

Water saturation of the formation's flushed zone (Sxo) is calculated using the Archie equation, but two variables are changed: mud filtrate resistivity $(R m f)$ in place of formation water resistivity and flushed zone resistivity $(R x o)$ in place of uninvaded zone resistivity $(R t)$ :

$$
S x o=\left[\left(a^{*} R m f\right) /\left(R x o^{*} \Phi^{m}\right)\right]^{1 / n}
$$


Sxo $=$ water saturation of the flushed zone

$R m f=$ resistivity of mud filtrate at formation temperature.

$R x o=$ shallow resistivity from a very shallow reading device such as Laterolog-8, Micro-spherically focused $\log (\mu \mathrm{SFL})$, or short normal logs.

$\Phi=$ porosity

$a=$ tortuosity factor $(\mathrm{a}=1.0$ for carbonate rocks)

$m=$ cementation exponent $(\mathrm{m}=1.65$ from $))$

$n=$ saturation exponent ( $\mathrm{n}$ assumed to be 2.0 )

Since $S h=(1-S w)$, and $S h r=(1-S x o)$, we can find the bulk-volume fraction of the oil displaced by invasion as $\Phi(S h-S h r)$, which equals to

$\Phi .(S x o-S w)$

\subsection{Bulk Volume of Water (BVW)}

The bulk volume water calculation depends on two essential parameters: such as water saturation of uninvaded zone $(\mathrm{Sw})$, and porosity as it is illustrated in the following equation: (Asquith and Krygowski, 2004)

$$
B V W=S w . \Phi
$$

Plotting of porosity versus water saturation values for a reservoir can be helpful in determining bulk volume of water variation and type of fluid production. If values of bulk volume of water in a formation at several depths are constant or very close to constant this will indicate that the reservoir is homogenous and of uniform lithologies. The reservoir in this case is at irreducible water saturation $\left(S w_{i r r}\right)$, which means that the water in the uninvaded zone does not move, because it is hold on grains by capillary pressure. Therefore, hydrocarbon production from a zone at irreducible saturation should be water free (Asquith and Krygowski, 2004). This will appear on the cross-plotting diagram as the BVW values (points) are falling in a coherent pattern and close or parallel to a specific hyperbolic line. The formation produces mostly oil. When the BVW readings points have random distributions over the cross-plotting diagram with no connection to a specific hyperbolic line. This will indicate that the formation is not at irreducible water saturation, and it will be producing either oil and water or $0 \%$ oil (all water) (Schlumberger, 1972; Serra, 1986; Asquith and Krygowski, 2004).

The porosity versus water saturation ( $\mathrm{Sw}$ ) cross plotting method is applied to the entire potential reservoir unit (A) of the Mauddud Formation in six wells: Kz-3, Kz-4, Kz-5, Kz-11, Kz-13 and Kz-14 (Fig. 4). In well Kz-3 the non-potential part of the reservoir unit (A) (Fig. 4A) has confined distribution to a specific hyperbolic line and indicates water saturation at the irreducible water saturation ( $\mathrm{Sw}_{\text {irr }}$ ). This is because these points represent the poorly porous part of the reservoir at which water held on by capillary pressure. Points of the potential layers of the reservoir unit (A) (solid points, Fig. 4A) have scattered distribution with respect to the hyperbolic line. These points fall to the right side of the diagram, at area of high-water saturation and porosity, which means movable water; therefore, the well is water producer. This result is understandable as well Kz-3 is located at the southeastern nose of the field, and almost beyond the hydrocarbon zone (see Fig. 2). At Well Kz-4 (Fig. 4B) some of the points are confined to a simple hyperbolic curve, indicating irreducible water of un-invaded zone and refer to water free hydrocarbon producing well. The figure also shows a group of points fall at the right most part of the figure. These points represent a movable water, because this well is located nearby the northwest end of the field at an area beyond the oil zone (Fig. 2), which represents a water saturated zone. Well, Kz-5, shows that most of the points fall in a fairly coherent pattern on the cross-plot diagram, approximating a specific hyperbolic curve which is belong to the irreducible water saturation (Fig. 4C). The distribution of the points refers to the water free hydrocarbon production. The few points shifted from the coherent pattern and fall to the right side of the figure represent a movable water saturation. 
These points are considered a small portion of the whole potential reservoir unit (A) as compared with the others points.

In well Kz-11, the points fall in a good coherent pattern on the hyperbolic curve (Fig. 4D). The pattern indicate that the formation water saturations are at the irreducible (Swirr) condition. This means that the well will produce water free hydrocarbons. Plotting also applied for well Kz-13 available data, as an additional support to the BVW evaluation. The points of this figure belong only to the lower and most porous part of reservoir unit (A), due to lack of some log data of the other parts. This part has very limited non-reservoir layer; thus, most of the data fall on high porosity field and low formation water saturation. Again, points distribution indicates irreducible formation water, and water free hydrocarbon productions. Evidently the location of both wells is at the crestal part of the structure, within the oil zone of the field (Fig. 2). Finally, the cross plotting of well Kz-14, shows that points fall in a good clustering pattern on the hyperbolic curve (Fig. 4F), which indicate that the formation waters saturation are at the irreducible (Swirr) condition. This means that the well will produce water free hydrocarbons in a perfect manner.

\subsection{Residual and Movable Hydrocarbons}

The calculated water saturation is used in evaluating hydrocarbon movability and its production. These calculations can be summarized by the following equations (Crains, 2015):

$$
\begin{array}{cl}
\text { Total hydrocarbon saturation: } & \mathrm{Sh}=1.00-\mathrm{Sw} \\
\text { Residual hydrocarbon saturation: } & \mathrm{Shr}=1.00-\mathrm{Sxo}
\end{array}
$$

Moveable hydrocarbon saturation

$$
\begin{gathered}
\mathrm{Smo}=\mathrm{Sh}-\mathrm{Shr} \\
\mathrm{Smo}=\mathrm{Sxo}-\mathrm{Sw}
\end{gathered}
$$

Where:

Sxo $=$ water saturation in invaded zone (fractional)

$\mathrm{Sw}=$ water saturation in un-invaded zone (fractional)

Shy $=$ hydrocarbon saturation in un-invaded zone (fractional)

$\mathrm{Shr}=$ residual hydrocarbon saturation in invaded zone (fractional)

Smo $=$ moveable hydrocarbon saturation (fractional)

The hydrocarbon saturation (Sh) of formation include both of movable and residual hydrocarbon, the former is recoverable hydrocarbons which can be produced and the latter left in reservoir and cannot be produced (Bates and Jackson, 1980). The evaluation of the three parameters (Shy, Shr, and Smo ) is very important in evaluating reservoir fluid production. The percentage volume (Bulk Volume) in terms of the reservoir of these parameters can be obtained by multiplying these parameters by the derived porosity (N-D Porosity) as follow (Rider, 1996). 

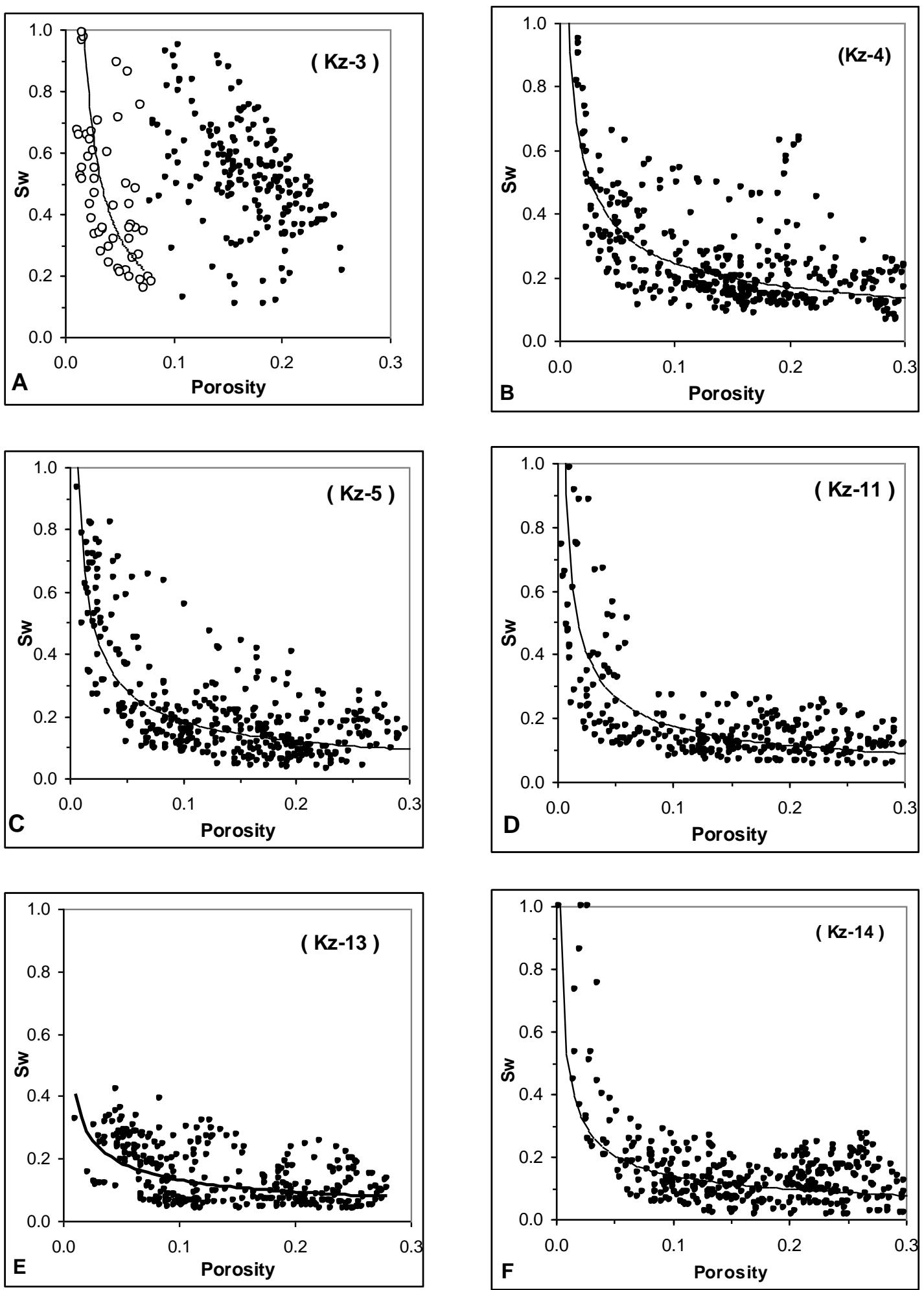

Fig. 4. Porosity versus water saturation cross plotting in the studied wells. All figures are showing close association with specific hyperbolic pattern, which indicate that the formation is at irreducible water saturation, except (A) and (B) of well Kz-3 and well Kz-4 respectively. Both show scatter pattern, which indicate water producing reservoir. At (A) open circles points represent non-reservoir layers and the solid dots are good reservoir layers 
Bulk Volume of water $=$ Sw. $\Phi$

Bulk Volume of hydrocarbons $=(1-\mathrm{Sw}) . \Phi$

Bulk Volume of movable hydrocarbons $=(\mathrm{Sxo}-\mathrm{Sw}) . \Phi$

Bulk Volume of residual hydrocarbons $=(1-$ Sxo $) . \Phi$

The results of the application of the above bulk volume calculations to the studied wells for the three Mauddud reservoir units (A, B, and C) were presented in Figs. 5 and 6. The outer curves represent the porosity and the blue color area represents the bulk volume of water saturation (Sw. $\Phi)$ which occupied fraction of porosity. The rest part of porosity area represents the fraction of porosity occupied by hydrocarbon saturations. The movable fraction illustrated by yellow color area, while the dark grey areas represents the residual or irreducible hydrocarbons.

\section{Discussion}

The following paragraph will discuss fluids bulk volumes and their movability in each reservoir unit of the Mauddud Formation, Khabbaz oil field.

\subsection{Unit A}

Unit (A) of the Mauddud reservoir represents the main reservoir zone all over the Khabbaz oil field. Due to its good reservoir quality, it was divided into subunits (A1, A2, A3, A4, A5 and A6) of good porosity horizons. The studied wells Well Kz-11, Kz-14, and Kz-5 show good ratio of bulk volume of hydrocarbons with respect to bulk volume of water (Fig.5). These wells are located at the apex of the structure within the oil zone area. All are characterized by good movable hydrocarbon (yellow area), particularly the lower part of the unit including subunits A4, A5 and A6, which have good thickness and low water saturation. Also, the upper part of wells Kz-11 and Kz-14 (subunit A1 and A2) have relatively high movable hydrocarbon.

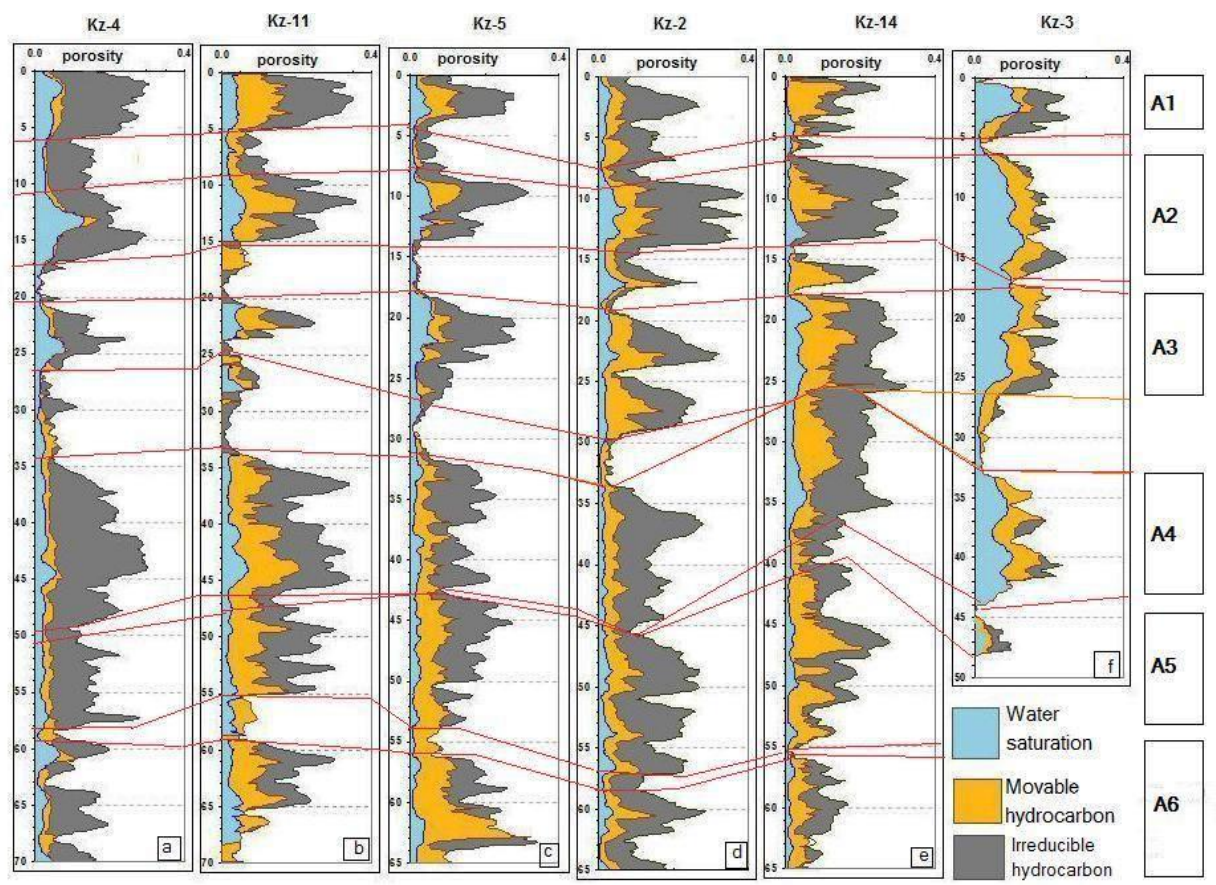

Fig. 5. Water saturation, hydrocarbon saturations (residual and moveable) of the studied wells of unit $A$, represented by its subunits (A1, A2, A3, A4, A5, and A6) 


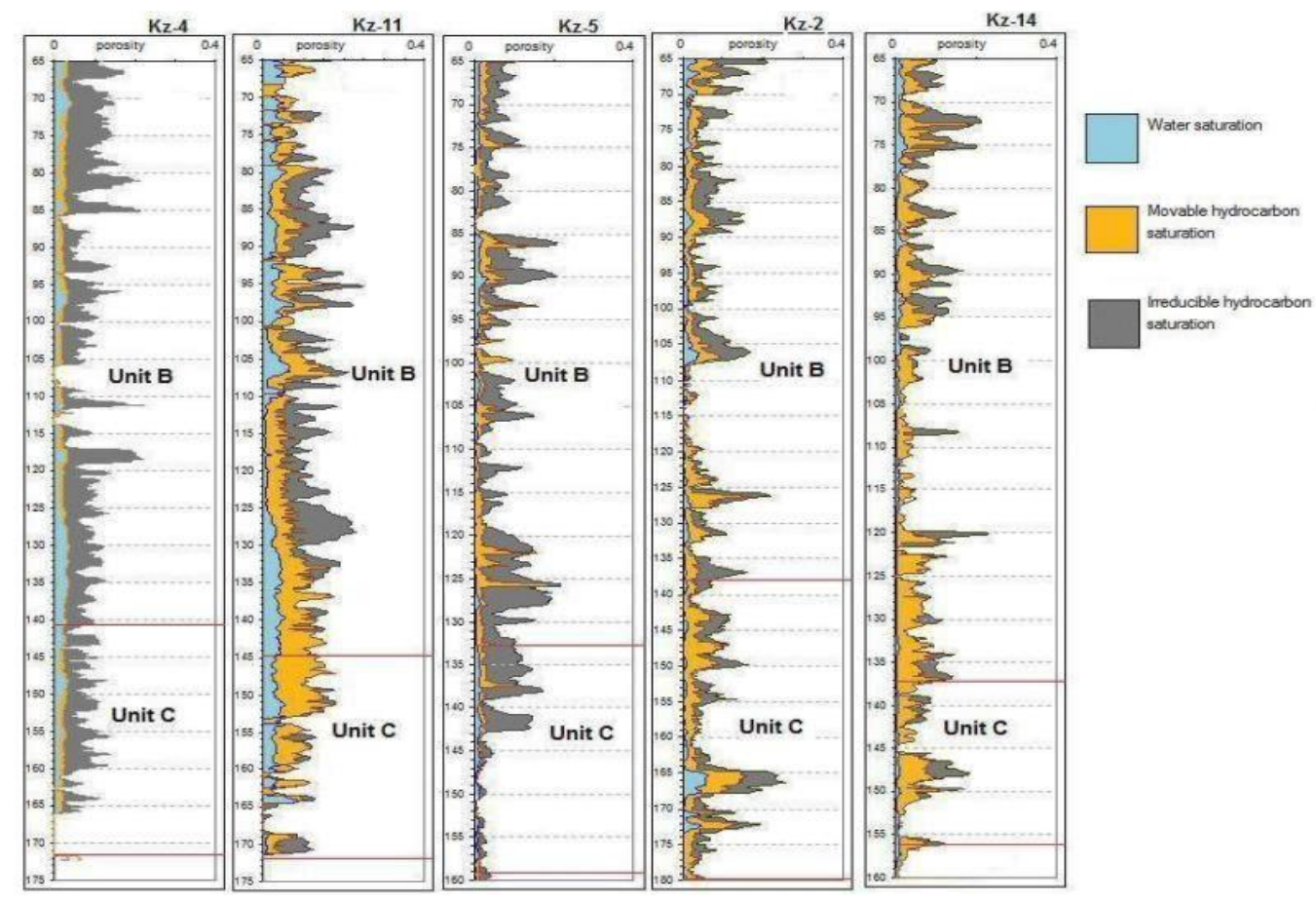

Fig. 6. Water saturation, residual and movable hydrocarbon saturation of the studied wells of units B and $\mathrm{C}$

The other wells Kz-2, Kz-3, and Kz-4 have relatively low and variable hydrocarbon saturation as well as high water saturation. These wells are located at the extreme end of the structure near its plunges and within the water zone or beyond the oil zone (Fig. 2). The reservoir section of unit A at the well Kz2 illustrate moderate movable oil particularly its two subunits A2 and A3. The section shows that the residual hydrocarbon (irreducible hydrocarbon) is dominating the section, with low water saturation and limited movable hydrocarbon. This is related to the situation of the well to the northeast limb of the structure close to the lateral oil-water interface. Similarly wells Kz-3 and Kz-4 have relatively highwater saturation and low movable hydrocarbon ratio all over the section of the unit. At Well Kz-4 residual hydrocarbon is dominating and at Kz-3 water saturation is dominating (Fig. 5).

\subsection{Units $B$ and $C$}

These two units (B) and (C) have unattractive reservoir quality as compared with unit A because of their relatively low porosity. The movable hydrocarbon ratio in both units at all wells is generally low despite the low water saturation ratio (Fig. 6). At well Kz-4 movable is neglected and only residual oil is markedly high. This is again due to the location of the well far beyond the oil pool (Fig. 2). Well, Kz11 has some movable hydrocarbons, especially at the lower part of unit B and upper part of unit (C). At well Kz-5, the two units $\mathrm{B}$ and $\mathrm{C}$ show rare movable hydrocarbon, while the two zones have high porosity. The residual oil is clearly dominant. for well $\mathrm{Kz}-2$, the two units $\mathrm{B}$ and $\mathrm{C}$ are characterized by low porosity and also low movable oil except at the lower part of unit $\mathrm{B}$ and the rest of unit $\mathrm{C}$ which show moderate movable oil. The two units at Kz-14 show relatively moderate movable hydrocarbons ratio, despite the relatively low porosity of the unit.

Conceivably the location of each well with respect to the oil zone, and the type of porosity and their connection nature seems to play significant role in controlling the nature of movable fluids regardless of the total value of the reservoir unit porosity. The total porosity values of the reservoir have negligible influence on fluids movability percentage ( $\mathrm{Gao}$ and $\mathrm{Li}, 2015)$. It is rather the permeability, pore 
geometry, and the effective pore-throat volume shows important influence on the reservoir fluids movability (Li et al., 2018).

\section{Conclusions}

Petrophysical analysis of the Mauddud reservoir using log data from six wells over the Khabbaz oil field shows that the hydrocarbon movability is variable vertically and laterally due to variable lithologies and heterogeneous distribution of petrophysical characters. Hydrocarbon movability is relatively high in wells located on the crestal part of the structure within the oil pool or close to it. Wells with limited hydrocarbon movability are located beyond the oil pool zone. Vertical variation in hydrocarbon movability shows a creatable trend with reservoir units' distribution and their lithologic characters which control pore geometry as well as permeability value and distribution.

\section{Acknowledgements}

The authors are indebted to the Geology Department of the Northern Oil Company, Kirkuk, of Iraq for providing most of the research original data. The authors are very grateful to the Editor in Chief Prof. Dr. Salih M. Awadh, the Secretary of Journal Mr. Samir R. Hijab. and the Technical Editors for their great efforts and valuable comments.

\section{References}

Abdulrahman, S., AlKubaisi, M., and Al-Shara'a, G. 2020. Formation evaluation for Jeribe Formation, in the Jeria Pika Gas Field. Iraqi Geological Journal, 53(2F), 83-93.

Al-Qayim, B., Qadir, F., and Al-Biaty, F., 2010. Dolomitization and porosity evaluation of the Cretaceous Upper Qamchuqa (Mauddud) Formation, Khabbaz oil field, Kirkuk area, northern Iraq. GeoArabia, 15 (4), $49-76$.

Al-Sadooni, F. 1978. Sedimentology and petroleum prospects of the Qamchuqa Group, Northern Iraq. Unpublished Ph. D. thesis, University of Bristol, UK.

APS Review, 2007. Iraq- The Main Fields In the North. Down Stream Trends. 17pp.

Asquith, G. and Krygowski, D., 2004. Basic Well Log Analysis. Methods in Exploration, American Association of Petroleum Geologists, Falls Church, Virginia.

Bates, R. L., and Jackson, J. A., 1980. Glossary of Geology. Second Edition. The American Geological Institute Publications.

Buday, T. 1980. The Regional Geology of Iraq, Stratigraphy and Paleogeography, Dar AL-Kuttib Publication House. University of Mosul, Iraq, 1, 445 p.

Bayphase, 2011. Iraq oil and Gas Industry Strategic Report. Fifth edition. 786 pp.

Crains, D., 2015. Manual of Petrophysical Analysis. Online Handbook.

Dickson, J.A. 1966. Carbonate identification and genesis as revealed by staining, Journal of Sedimentary Research, 36 (2), 491- 505.

Gao, H., and Li, H., 2015. Determination of movable fluid percentage and movable fluid porosity in ultra-low permeability sandstone using nuclear magnetic resonance (NMR) technique. Journal of Petroleum Science and Engineering, 133,

Hamada, G. 2006. Identification of Hydrocarbon Moveability and Type from Resistivity Logs. SPE Technical Symposium, Dhahran.

Jassim, S. Z., and Goff, J., 2006. Geology of Iraq. Dolin, Prague and Moravian Museum, Brno.

Khudhair, M., and Al-Zaidy, A. 2018. Petrophysical properties and reservoir development of Albian succession in Nasiriyah oil field, Southern Iraq. Iraqi Bulletin of Geology and Mining, 14(2), 61-69.

Li, P., 2018. Occurrence characteristics and influential factors of movable fluids in pores with different structures of Chang $6_{3}$ reservoir, Huaqing oil field, Ordos Basin, China. Marine and Petroleum Geology, 97(11), 480492.

Mamaseni, W. 2020. Petroleum potentiality and petrophysical evaluation of the Midd Jurassic Sargelu Formation, Northern Iraq. Iraqi Geological Journal, 53(2D), 77-93. 
Rider, M., 1996. The Geological Interpretation of well logs, 2nd. Ed. Rider French Consulting Ltd. Aberdeen and Sutherland, UK.

Sadooni F., and Al-Sharhan, A., 2003. Stratigraphy, microfacies, and petroleum potential of the Mauddud Formation (Albian-Cenomanian) in the Arabian Gulf basin. American Association of Petroleum Geologists, 87(10), 1653-1680.

Serra, O., 1986. Advanced Interpretation of Wireline Logs. Schlumberger book Series, New York.

Shclumberger, 1972. The Essentials of Log Interpretation Practice. New York.

Sun, Li., Wu, W., Huang, B., Gao, Y., Yan, J., and Huang, H. 2019. Occurrence characteristics and main controlling factors of movable fluids in Chang 81 reservoir, Maling Oilfield, Ordos Basin, China. Journal of Petroleum Exploration and Production Technology, 9, 17-29.

Verma, M., Ahbrandt, T., and Al-Gailani, M. 2004. Petroleum reserves and undiscovered resources in the total petroleum systems of Iraq: reserve growth and production implications. GeoArabia, 9 (3), 51-74. 